\title{
BMJ Open Spatial analysis of the prevalence of obesity and overweight among women in Ghana
}

\author{
Killian Asampana Asosega (D) , ${ }^{1}$ Atinuke Olusola Adebanji, ${ }^{2}$ Iddrisu Wahab Abdul ${ }^{1}$
}

To cite: Asosega KA, Adebanji A0, Abdul IW. Spatial analysis of the prevalence of obesity and overweight among women in Ghana. BMJ Open 2021;11:e041659. doi:10.1136/ bmjopen-2020-041659

- Prepublication history for this paper is available online. To view these files, please visit the journal online (http://dx.doi org/10.1136/bmjopen-2020041659).

Received 14 June 2020 Revised 23 December 2020 Accepted 06 January 2021

\section{Check for updates}

(C) Author(s) (or their employer(s)) 2021. Re-use permitted under CC BY-NC. No commercial re-use. See rights and permissions. Published by BMJ.

${ }^{1}$ Mathematics and Statistics, University of Energy and Natural Resources, Sunyani, Ghana ${ }^{2}$ Department of Statistics and Actuarial Science, Kwame Nkrumah University of Science and Technology, Kumasi, Ashanti, Ghana

Correspondence to Killian Asampana Asosega; killian.asosega@uenr.edu.gh

\section{ABSTRACT}

Objective Identifying hot spots for the overweight aids in effective public health interventions due to the associated public health burden and morbidities. This study, therefore aimed to explore and determine the spatial disparities in the overweight/obesity prevalence among women in Ghana. The study also aims at modelling the average body mass index (BMI) values using the spatial regression and the performance compared with the standard regression model.

Design This is a cross-sectional study using data from the 2014 Ghana Demographic and Health Survey (GDHS). Setting The study was set in Ghana.

Participants and methods Data on 4393 non-pregnant women aged 15-49 years from the 2014 GDHS. Both global (Moran's I) and the local indicators for spatial dependence were examined through the mapped BMI values across the country by clusters. An estimated spatial lag model was used to explain the spatial differences in the average body sizes of women.

Results The overall prevalence of overweight/obesity among reproductive women in Ghana was $35.4 \%$, and this was highly prevalent among educated women $(p<0.001)$, those from wealthy households $(p<0.001)$ and dwelling in an urban setting $(p<0.001)$. Significant clustering (Moran's $I=0.3145, p<0.01$ ) of overweight/obesity was observed with hot spots (clustering) in Greater Accra, Central, Western and Ashanti regions. The spatial lag model was the best fit based on the Likelihood ratio test and the Akaike information criterion and Bayesian information criterion values. The mean age of women and household wealth were significant factors accounting for the increase in the average cluster body size (BMI) of women and the spatial differences.

Conclusion The prevalence of overweight/obesity was high and spatially clustered in the southern, middle and coastal regions. Geographic specific and effective public health interventions and strategies are needed to address the growing morbidity burden associated with the rise in the average body sizes of reproductive women.

\section{INTRODUCTION}

Recent global trends show an increase in the average body size is posing serious health problems in both developed and developing countries $^{1}$ and in alarming proportions in sub-Saharan Africa (SSA). ${ }^{2-6}$ Overweight and obesity are consequences of an unhealthy

\section{Strengths and limitations of this study}

The findings of the study provide the geographical locations (hot spots) of the overweight and obesity health burden requiring appropriate public health interventions.

With a nationwide survey data, results and findings of this study are a fair representation of the entire Ghanaian population.

- A much larger sample devoid of incomplete data could further enhance the findings of the study.

- The lack of geographical data on individual women and their households limits the scope of the findings to the cluster level.

increase in body size, which are significant risk factors for a variety of chronic diseases such as cardiovascular conditions, cancer as well as diabetes ${ }^{7-9}$ with high associated mortality rates. ${ }^{10} 11$

According to Biadgilign et al, Popkin et al and Ajayi et al, ${ }^{7213}$ overweight and obesity were originally considered health problems in high-income countries, are on the rise in low-income and middle-income countries, especially in urban settings and Ghana is not exempted. $\mathrm{WHO}^{14}$ defined overweight and obesity as the excessive buildup of fat which poses a risk to health. Overweight and obesity are determined through the body mass index (BMI), which is the ratio of a person's weight (in kilograms) to the height squared (in metres). BMI value of at least $30 \mathrm{~kg} / \mathrm{m}^{2}$ is considered to be obese while, it is overweight when $25 \mathrm{~kg} / \mathrm{m}^{2} \leq \mathrm{BMI}<30 \mathrm{~kg} / \mathrm{m}^{2} .{ }^{14} \mathrm{BMI}$ of an individual is an efficient determinant of body fatness and is mostly used to screen for weight categories associated with health problems.

Overweight and obesity are currently on the increase in most developing countries and most especially in urban areas where livelihoods and conditions in general are relatively better than in rural settings. ${ }^{4-101315}$ Kelly et $a l^{16}$ estimated and projected the overweight 
and obesity prevalence in the world and various regions in 2005 to 2030 and observed an overall prevalence of $23.2 \%$ and $9.8 \%$ of overweight and obesity, respectively around the entire world, and projected the overweight and obesity populations will exceed 2.16 billion and 1.12 million, respectively by 2030 .

The trends of overweight and obesity prevalence and epidemic among children are also on the rise in Ghana and in most part of the SSA. ${ }^{17-19}$ Mohammed and Vuvor ${ }^{20}$ observed that childhood obesity and its related consequences have raised concerns across the world due to its clinical and public health burdens in developing economies. The urban populations recorded higher risks of both overweight and obesity than rural populations with Greater Accra and Ashanti regions recording most of the overweight and obesity prevalence of $55.2 \%$ and $43.4 \%$, respectively. The highest risks are attributed to the associated high level of urbanisation in these regions. ${ }^{8921}$

The high overweight/obesity prevalence among women in Africa are also linked to sociocultural beliefs and socioeconomic status of women. In Toselli et al, ${ }^{11}$ it was opined that among Egyptian women, large body size is perceived to signify wealth and fertility. Arojo and Osungbade ${ }^{21}$ also admitted that, in Africa obesity and overweight are perceived culturally and socially as signs of success, beauty, happiness and wealth. Besides the social-cultural perceptions associated with an increase in average body size and its related health consequences, there is an established association between wealth, parity and overweight or obese status. ${ }^{22}$ Again Price $e t$ al, Diendéré et al and Kim $e t a l^{8922}$ observed a significant positive association between overweight and parity in wealthy women in developed countries. However, in the same study, a negative relationship was also observed between poor women and overweight and accounted for the wasting effect on women.

Several studies have focused and established the predisposing risk factors and causes of overweight/obesity among women with little attention on the spatial distribution facet of overweight/obesity in Ghana. ${ }^{10} 152023$ Hence, the present study aimed to (1) explore and determine the overall and local spatial dimension of the overweight and obesity among reproductive women in Ghana, (2) determine the factors and their effects for the spatial disparities in the average body sizes among Ghanaian women using the standard 2014 nationwide Ghana Demographic and Health Survey (GDHS) data and (3) compared the spatial models performance to the standard regression model.

\section{METHODS}

\section{Data and study design}

This study adopted the 2014 GDHS conducted between September and November 2014. The GDHS, a nationwide household survey collected data in line with the cross-sectional design protocols. ${ }^{24}$ The survey used a two-stage probability sampling technique across the then 10 regions in Ghana. ${ }^{24}$ The first stage of the sampling method involved the selection of enumeration areas (EAs). In all, 427 EAs (clusters) were selected across Ghana comprising of 211 and 216 rural and urban areas, respectively. ${ }^{24}$ The second stage of the probability sampling approach involved the systematic selection of households in the preselected EAs. Household-listing activities in the selected EAs were undertaken between January and March 2014. Eligible households included in the survey were randomly chosen from the list, an average of 30 households were selected in each EA to constitute the sample of 12851 households for the survey. The survey further randomly selected 9396 reproductive women from the households. ${ }^{24}$

\section{Study area}

Ghana is the setting for this study. Ghana is an independent multiparty democratic country in West Africa along the coast of the Gulf of Guinea and the Atlantic Ocean. Ghana covers a land area of $238535 \mathrm{~km}^{2}$. Ghana share boundaries with Ivory Coast, Togo and Burkina Faso in the West, East and North, respectively. The population of Ghana is estimated at 31 million with its capital city, ${ }^{25}$ Accra in the Greater Accra region. Ghana is one of the fast-growing economies in the West African subregion and coupled with its strong democratic political system, and achievements in recent times have made it a peaceful model country for others to emulate in Africa.

Ghana has since independence undertaken several economic development programmes across all regions towards eradicating poverty, malnutrition and hunger, illiteracy, maternal and infant mortality among others. Despite all these efforts by the respective governments, there are economic or poverty inequalities and disparities between the urban and rural parts of Ghana. The rural inhabitants are three times likely to be poor compared with their urban counterparts. Also, poverty levels are high in the northern parts compared with the southern parts. ${ }^{24} 26$

\section{Study sample}

This study focused on individual reproductive women (15-49 years) aggregated at the cluster level as the unit of analysis for the spatial analysis. The initial dataset comprised of 9396 interviewed women selected from 11835 households in the 2014 GDHS. Out of the 9396 women interviewed, women who responded 'yes' they are pregnant (406) and those with either height $(\mathrm{cm})$ or weight (kg) missing (4596) were excluded. The study sample therefore reduced to 4393 reproductive women with complete information. See figure 1 for details.

\section{Study variables}

The BMI is used as the outcome of the study. The BMI of each of the 4393 women from the 2014 GDHS is determined from their anthropometric measurements (weight (in kilograms) and height (in centimetres)). The explanatory variables include maternal age, household wealth and number of children all averaged (centred) 


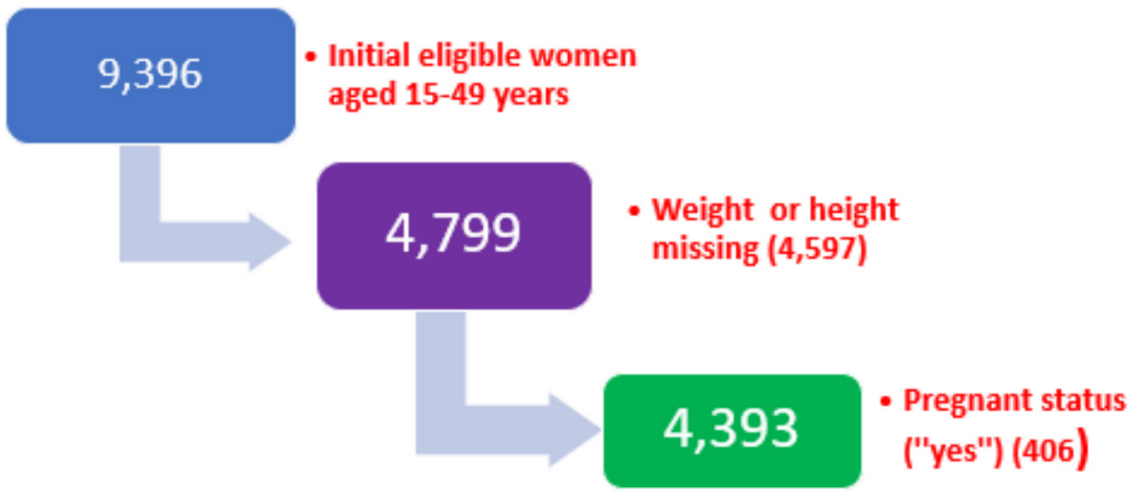

Figure 1 Flow diagram.

at the cluster level. Preliminary analysis on the association between sociodemographic factors such as educational attainment (no education, primary, secondary and higher), marital status (single, married, cohabiting and divorced/separated/ widowed), wealth status (poor, middle and rich) and body size category (BMI).

\section{Patient and public involvement}

No patient was involved in this study.

\section{Ethical consideration}

The 2014 GDHS protocol was reviewed and given approval by the Institutional Review Board of ICF International and Ghana Health Service Ethical Committee. Also, informed consent of eligible women was duly obtained before they were interviewed. ${ }^{24}$

\section{STATISTICAL ANALYSIS}

\section{Spatial regression models}

Spatial regression models are extensions of the standard regression models incorporated with a spatial dependence structure when the independence assumption required in standard regression models is violated. ${ }^{27}$ Ordinary least square (OLS) estimates become biased and inconsistent if spatial error structures are not accounted for in the model. ${ }^{28-30}$ Various models attempt to deal with spatial dependence; the most commonly used are spatial lag and spatial error models (SEMs). ${ }^{29} 31$

The SLM is appropriate when the focus is on the spatial interaction of the dependent variable. In this case, the dependent variable y has the spatial structure. The SLM is a spatial autoregressive model that includes spatially lagged dependent variable $(\mathrm{Wy})$, which is the weighted average of corresponding neighbouring values. Anselin $^{29} 31$ defined the spatial lag regression model also known as the autoregressive model in (1) as

$$
\mathrm{y}=\rho \mathrm{Wy}+\mathrm{X} \beta+\varepsilon
$$

where

$\mathrm{y}$ is the vector of dependent variable $(\mathrm{n} \times 1)$,

$\mathrm{x}$ the matrix of the independent variable $(\mathrm{n} \times(\mathrm{k}+1))$,

$\beta$ the vector of regression coefficient parameters $((\mathrm{k}+$ 1) $\times 1$ ), $\rho$ thelag coefficient parameter for the dependent variable,

$\varepsilon$ the error term $n \times 1$ and

$\mathrm{w}$ the weight matrix $(\mathrm{n} \times \mathrm{n})$.

And the SLM can be further expressed as:

$$
\begin{gathered}
(\mathrm{I}-\rho \mathrm{W}) \mathrm{y}=\mathbf{X} \beta+\varepsilon \\
\mathrm{y}=(\mathrm{I}-\rho \mathrm{W})^{-1}(\mathrm{X} \beta+\varepsilon)
\end{gathered}
$$

The independent variables $\mathrm{X}$ accounts for the variations in the dependent variable not explained by the neighbouring values.

The SEM is appropriate when the interest is in correcting for the spatial dependence or autocorrelation due to the use of spatial data. The SEM includes the spatially corrected errors due to unobserved features or omitted variables associated with the locations of the observations. The SEM was defined by Anselin ${ }^{29}$ as:

$$
\mathrm{y}=\mathbf{X} \beta+\varepsilon
$$

And the errors are spatially corrected by

$$
\varepsilon=\lambda \mathrm{W} \varepsilon+\mathrm{u}
$$

where

$\lambda$ is the spatial lag of the error coefficient,

I the identity matrix $(\mathrm{n} \times \mathrm{n})$

With the $\mathrm{u}$ assumed to be normally distributed with $\mathrm{E}(\mathrm{u})=0, \mathrm{E}\left(\mathrm{u}^{\prime} \mathrm{u}\right)=\sigma^{2} \mathrm{I}$

The SEM is simplified to obtain

$$
\mathrm{y}=\mathrm{X} \beta+(\mathrm{I}-\lambda \mathrm{W})^{-1} \mathrm{u}
$$

\section{Spatial dependence measure (Moran's I)}

The Moran's autocorrelation coefficient denoted as Moran's I mostly used in spatial analysis is an extension of Pearson's correlation coefficient. ${ }^{32-34}$ In the study of spatial patterns and processes, it is expected that close observations are more likely to be similar than those far apart. It is usual to associate a weight $\left(\mathrm{w}_{\mathrm{ij}}\right)$ to each pair $\left(\mathrm{x}_{\mathrm{i}}, \mathrm{x}_{\mathrm{j}}\right)$ which quantifies the spatial pattern. ${ }^{28} 3233$ The Moran's I defined in (7) as:

$$
I=\sum_{i} \sum_{j} w_{i j} \frac{\sum_{i} \sum_{j} w_{i j}\left(x_{i}-\bar{x}\right)\left(x_{j}-\bar{x}\right)}{\sum_{i}\left(x_{i}-\bar{x}\right)^{2}}
$$


The Moran's I range from -1 through 0 to +1 . Where the value of +1 signifies clusters with high BMIs are close to clusters with similar high BMI values while a value of -1 indicates high values are near to low values of BMI and 0 means no spatial autocorrelation. The significance of the computed Moran's I is tested at 5\% level of significance. In this current study, neighbours are defined based on the distance $\left(\mathrm{d}_{\mathrm{ij}}\right)$ between two observations (clusters). These weights will take value of 1 if $d_{i j}<D$ for close neighbours, and 0 otherwise and also set $\mathrm{w}_{\mathrm{ii}}=0$. Where $\mathrm{D}$ is the mean distance for all the pair of clusters in the study and the farther the distance between the observations $i$ and $j$ the smaller the influence they have on each other.

\section{Measures of model selection}

According to Lu and Zhang, ${ }^{35}$ when the model parameters are estimated by maximum likelihood estimation (MLE), a likelihood ratio test (LRT) can be employed to examine whether the SLM or SEM makes a significant improvement in model fitting over OLS. The LRT statistic follows the $\chi^{2}$ distribution with the $\mathrm{df}$ equal to the number of additional parameters in the more complex model.

The Akaike's 1974 information criterion (AIC) and Schwarz's Bayesian Information criterion (BIC) are widely employed in models fitting and selection problems. The AIC scores model goodness of fit by the maximum value of the log-likelihood function and the total number of parameters to be estimated in the model(s), and is biased towards parsimonious models. The AIC is defined in (9):

$$
\mathrm{AIC}=-2 \mathrm{~L}+2 \mathrm{~K}
$$

The BIC evaluates the overall fit of a model and allows the comparison of both nested and non-nested models. The BIC identifies the model that is more likely to generate the observed data and tend to penalise complex models more heavily than simpler models. The BIC value for a given model is expressed in (10):

$$
\mathrm{BIC}=-2 \mathrm{~L}+\mathrm{k} \ln (\mathrm{N})
$$

where, $\mathrm{L}$ is the value of the log-likelihood function at its maximum value and $\mathrm{k}$ is the number of parameters in the model. Smaller values of both measures (AIC and BIC) for a model, the better the fit. ${ }^{36-38}$

The spatial dependence was examined by the mapped BMI values across the country specified by the cluster coordinates through the global indicator (Moran's I) and the local indicator of spatial autocorrelation plots determine and classify the type of local spatial clustering occurring (whether low-low, low-high, high-high). Spatial models were fitted using the BMI values as a response variable with demographic and socioeconomic variables (maternal age, wealth factor scores and the parity of the women) as covariates using the method of MLE to incorporate the spatial dependence ${ }^{34}$ in BMI values of women across Ghana. Analyses were performed using Stata V.12.0, GeoDA and ArcGIS V.10.2.2.

\section{RESULTS}

\section{Preliminary results}

The BMI distributions showed the prevalence of over-

\begin{tabular}{|c|c|c|c|c|}
\hline Weight category & Underweight & Normal & Overweight & Obese \\
\hline & $286(6.5 \%)$ & 2549 (58.0\%) & 1007 (22.9\%) & $551(12.5 \%)$ \\
\hline \multicolumn{5}{|l|}{ Place of residence } \\
\hline Urban & $124(5.7 \%)$ & $1054(48.5 \%)$ & $597(27.4 \%)$ & $400(18.4 \%)$ \\
\hline Rural & $162(7.3 \%)$ & $1495(67.4 \%)$ & 410 (18.5\%) & $151(6.8 \%)$ \\
\hline \multicolumn{5}{|l|}{ Educational attainment } \\
\hline No formal education & $67(6.3 \%)$ & 715 (67.6\%) & 194 (18.4\%) & $81(7.7 \%)$ \\
\hline Primary & $72(8.6 \%)$ & $488(58.1 \%)$ & $178(21.2 \%)$ & $102(12.1 \%)$ \\
\hline Secondary & $136(6.0 \%)$ & $1251(55.2 \%)$ & 564 (24.9\%) & $317(14.0 \%)$ \\
\hline Higher & $11(4.8 \%)$ & $95(41.7 \%)$ & $71(31.1 \%)$ & $51(22.4 \%)$ \\
\hline \multicolumn{5}{|l|}{ Household wealth status } \\
\hline Poor & $179(9.4 \%)$ & $1387(72.7 \%)$ & $281(14.7 \%)$ & $61(3.2 \%)$ \\
\hline Middle & $39(4.3 \%)$ & $510(56.2 \%)$ & $234(25.8 \%)$ & $124(13.7 \%)$ \\
\hline Rich & $68(4.3 \%)$ & $652(41.3 \%)$ & $492(31.2 \%)$ & $366(23.2 \%)$ \\
\hline \multicolumn{5}{|l|}{ Marital status } \\
\hline Married & $85(4.4 \%)$ & $997(52.0 \%)$ & $524(27.3 \%)$ & $313(16.3 \%)$ \\
\hline Widowed/divorced & $15(4.6 \%)$ & $130(40.1 \%)$ & 104 (32.1\%) & 75 (23.1\%) \\
\hline Never married & $163(10.2 \%)$ & $1098(68.7 \%)$ & $242(15.1 \%)$ & 95 (5.9\%) \\
\hline Cohabiting & $23(4.2 \%)$ & 324 (58.7\%) & 137 (24.8\%) & 68 (12.3\%) \\
\hline
\end{tabular}
weight and obesity among women stood at $22.9 \%$ 
Table 2 Test of association statistics

\begin{tabular}{lccc}
\hline $\begin{array}{l}\text { Demographic } \\
\text { characteristics }\end{array}$ & $\chi^{2}$ statistic & df & P value \\
\hline Place of residence & 202.543 & 1 & $<0.001$ \\
\hline Educational background & 86.645 & 3 & $<0.001$ \\
Household wealth status & 509.325 & 2 & $<0.001$ \\
Marital status & 256.082 & 3 & $<0.001$ \\
\hline
\end{tabular}

and $12.5 \%$, respectively as presented below in table 1 . Although, more than half of women $(58.0 \%)$ were in the normal body size category $\left(18.5 \mathrm{~kg} / \mathrm{m}^{2} \leq\right.$ BMI $\leq 24.99$ $\mathrm{kg} / \mathrm{m}^{2}$ ), a significant proportion $(6.5 \%)$ of women are still underweight $\left(\mathrm{BMI}<18.5 \mathrm{~kg} / \mathrm{m}^{2}\right)$.

Overweight and obesity prevalence differ among women in respect of some demographic and socioeconomic differences. The overweight and obesity rates among urban women were $27.4 \%$ and $18.4 \%$, respectively compared with $18.5 \%$ of overweight and $6.8 \%$ obese in the rural settings. The results from the test for association presented in table 2 showed a significant $(\mathrm{p}<0.001)$ association between educational attainment of women and body weight category. Women with high levels of education have a higher risk of being overweight/obese by $53.5 \%$ compared with $39 \%, 33 \%$ and $26 \%$ for secondary, primary and non-educated women, respectively. More significantly, the highly educated women were more than twice likely to be obese compared with those with no formal education.

The prevalence of overweight and obesity is higher in the rich than the poor $\left(\chi^{2}=509.325, \mathrm{p}<0.001\right)$ as the rich are three times $(54 \%)$ more at risk of being obese/ overweight relative to the poor $(18 \%)$. The results further showed that, single women were relatively less probable $(30 \%)$ to be overweight or obese compared with married women $(43.6 \%)$, widowed/divorced $(55 \%)$ and cohabiting $\left(37.1 \%, \chi^{2}=256.082, \mathrm{p}<0.001\right)$. The results in table 2 indicate that, being married or cohabiting have a direct relation with the chance of being obese or overweight and the burden worsens when these women are later divorced or widowed.

The alarming health burden associated with the observed high BMI values of women across the country cannot be over emphasised as evident in figure 2. Most of the overweight clusters are located in the coastal, and southern regions and some few in the middle part. In addition, a significant number of the obese clusters are situated in the Greater Accra region, the capital of country which is most developed. The coastal and southern regions are considered hot spots for the overweight and obesity health burden in Ghana requiring urgent attention.

\section{Further results}

The average cluster BMI values for women are spatially distributed with a significant Moran's I value of 0.3145 $(\mathrm{p}<0.05)$. The results in table 3 show significant clustering in the mean BMI values of the clusters in Ghana. The significant clustering signified how nearby women turn to have similar body sizes than those far apart. The observed spatial dependence in the average BMI values suggests spatial models as candidate models to best explain the overweight/obesity prevalence differences in Ghana.

The spatial clustering was further evident and highlighted in figure 3. Most clusters in the north showed low-low (normal BMI) similarity coupled with some dissimilar clusters observed mostly in the middle parts. The high-high hot spots for the overweight burden in Ghana are significantly located in the Greater Accra, Central, Eastern and Ashanti regions of Ghana.

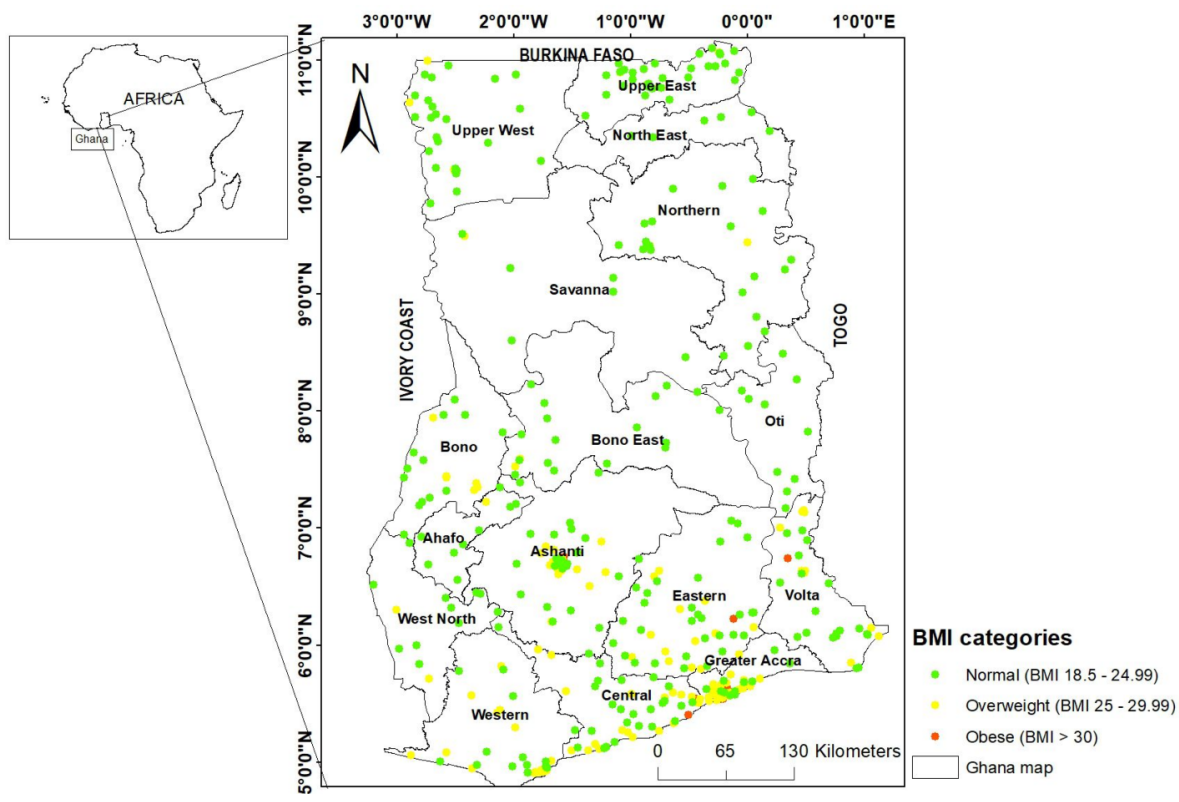

Figure 2 BMI status of clusters. BMI, body mass index. 
Table 3 Moran's I test Statistics

\begin{tabular}{llll}
\hline Moran's I & SE & Z value & Significance \\
\hline 0.3145 & 0.0195 & 16.1859 & 0.005 \\
\hline
\end{tabular}

Results on the estimated OLS and spatial models together with goodness-of- fit indicators (LRT, AIC and BIC) are presented in table 4 . The models result showed and established some form of spatial dependence; either in the average BMI values (SLM) or errors (SEM). The LRT showed that, the spatial models (SLM or SEM) are better fits $(\mathrm{p}<0.05)$ than the OLS model.

The SLM was the best model with the least AIC and BIC values of 1720.53 and 1740.01, respectively (table 3). The average maternal age, household wealth and the lagged IBM of the clusters were significant $(p<0.05)$ determinants of the differences in overweight/obesity in women, but the mean number of children per cluster was insignificant $(p>0.05)$ to the average body sizes of women. The significant predictors in the SLM had positive coefficients, signifying a direct association between the mean body size (BMI) of women in a cluster to the mean age and wealth score of the cluster. These direct associations observed suggest that advancement in age of women coupled with an improved economic status of their households increase their risk of gaining more weight which subsequently leads overweight and obesity if not checked.

\section{DISCUSSION}

The growing trend of overweight/obesity across the globe observed in Popkin et al and Adom et al ${ }^{12}{ }^{17}$ are consistent with findings in this current study with the risk of being overweight or obese at $35.4 \%$ (22.9\% overweight and $12.5 \%$ obese). The risk of overweight/obese

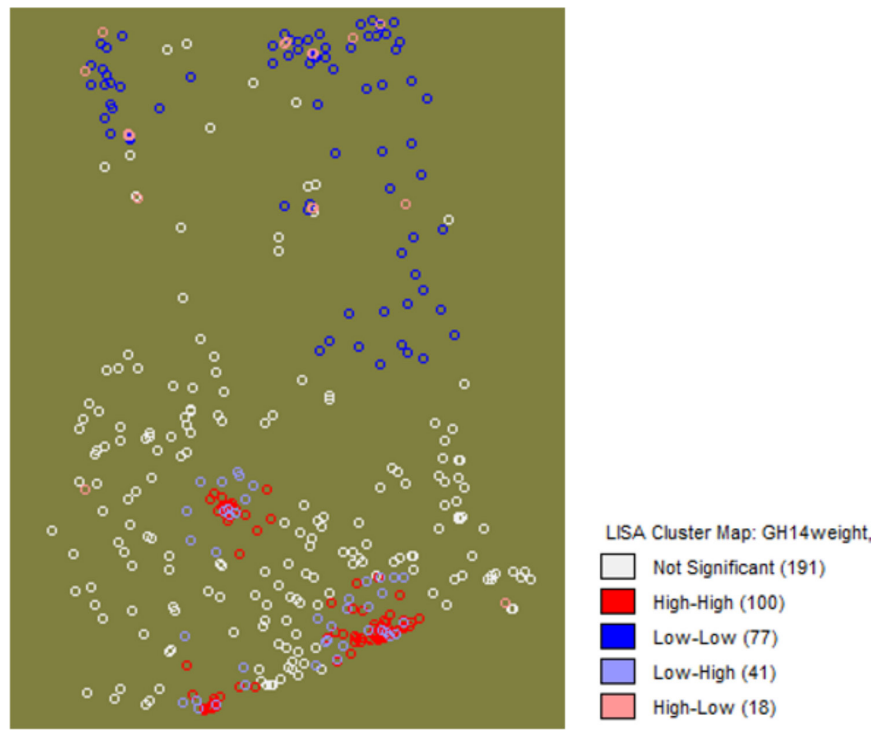

Figure 3 Significant clustering of clusters. LISA, local indicator of spatial autocorrelation.

\begin{tabular}{|c|c|c|c|}
\hline Model & OLS & SLM & SEM \\
\hline \multirow[t]{2}{*}{ Intercept } & $20.3164^{\star \star \star}$ & $14.9808^{\star \star \star}$ & $20.3511^{\star \star *}$ \\
\hline & $(0.8883)$ & (1.1289) & $(0.8829)$ \\
\hline \multirow{2}{*}{$\begin{array}{l}\text { Maternal average } \\
\text { age }\end{array}$} & $0.1514^{\star \star *}$ & $0.1469^{\star \star \star}$ & $0.1460^{\star \star \star}$ \\
\hline & $(0.0354)$ & $(0.0347)$ & $(0.0352)$ \\
\hline \multirow{2}{*}{$\begin{array}{l}\text { Average number of } \\
\text { children }\end{array}$} & -0.1419 & -0.1517 & -0.1015 \\
\hline & (0.1291) & $(0.1270)$ & $(0.1312)$ \\
\hline \multirow[t]{2}{*}{ Household wealth } & $0.0125^{\star \star \star}$ & $0.0108^{\star \star \star}$ & $0.0121^{\star \star \star}$ \\
\hline & $(0.0034)$ & $(0.004)$ & $(0.0038)$ \\
\hline \multirow[t]{2}{*}{ Lagged IBM ( $\rho)$} & & $0.2248^{\star \star *}$ & \\
\hline & & $(0.0678)$ & \\
\hline \multirow[t]{2}{*}{ Lagged error $(\lambda)$} & & & $0.2544^{\star *}$ \\
\hline & & & $(0.1086)$ \\
\hline $\mathrm{AlC}$ & 1728.97 & 1720.53 & 1724.07 \\
\hline $\mathrm{BIC}$ & 1748.20 & 1740.01 & 1740.30 \\
\hline LRT & & $10.4468^{\star * *}$ & $4.8998^{*}$ \\
\hline
\end{tabular}

${ }^{*} \mathrm{p} \leq 0.05,{ }^{* *} \mathrm{p} \leq 0.01,{ }^{* * *} \mathrm{p} \leq 0.001$.

AIC, Akaike information criterion; BIC, Bayesian information criterion; LRT, likelihood ratio test; OLS, ordinary least square; SEM, spatial error model; SLM, spatial lag model.

is higher among urban women than rural counterparts (45\% for urban vs $26 \%$ for rural) which are attributed to the rapid developments and economic improvements in the urban settings. The general increase in body size could be attributed to the sociocultural perceptions associated with bigger body images in some traditions in the African context. ${ }^{1139}$ Moreover, contrary to the conclusions made by Ziraba et $a l,{ }^{40}$ women with higher educational background have a higher risk (53.4\%) of being obese or overweight than women with primary $(30.3 \%)$ or no formal education $(22.5 \%)$. The results further indicate a positive relationship between educational level and increase in body size of women in Ghana. Findings made in the present study contradict of conclusions, ${ }^{23}$ where no association was established between overweight/obesity and educational status of women in some parts of Ghana.

Moreover, consistent with the conclusions in Price et $a l$, Arojo and Osungbade, Seidell and Halberstadt ${ }^{821} 41$ in which they observed a relationship between wealth of households and the average body size of women across various African traditions, the overweight/obesity risk prevalence is related to increase in household wealth of women. The married, widowed or divorced and cohabiting women have a higher risk of being obese or overweight than single women. This observation can be attributed to the attractiveness model of body size and marital status where married women are less likely to be very concerned or perturbed about their body size since they are not actively seeking for marriage suitors. ${ }^{42-45}$ In a related study, Benkeser et al, Wilson and Teachman and 
Weight ${ }^{23445}$ concluded that being married and having at least two children increased the risk of women becoming overweight or obese than unmarried women without children. Also, the prevalence and health burden of being overweight/obese among women turn to assume alarming proportions when these women lose their partners or are divorced due to the emotional and psychological stress among other underlying factors. Agofure and Yemane Nguse $^{346}$ opined that the continuous rise in overweight/ obesity prevalence across most economies in the SSA, including Ghana are likely to assume epidemic proportions in the near future if not curtailed immediately.

The prevalence of overweight/obesity among women in Ghana is spatially distributed as presented in figures 2 and 3. The observed spatial dependence confirms the assertion by $\mathrm{Cliff}^{30}$ that, 'close observations are likely to be similar than observations far apart'. Significant clustering (Moran's I=0.3145 $(\mathrm{p}<0.05)$ ) of women with high BMI values were observed in the Greater Accra, Central, Western and Ashanti regions. The hot spot regions are also the relatively developed regions and goes to confirm the findings in Akarolo-Anthony et al, Toselli et al and Ajayi $e t a l^{t 11} 13$ who attributed rapid urbanisation and modernisation to the escalating overweight and obesity prevalence and health morbidity burden in developing nations. The northern and some isolated parts of the middle parts recorded the low-low (normal-normal) average body sizes.

The SLM best (minimum AIC and BIC values) described the differences in the average body sizes of women. The mean age of women and household wealth are significant $(p<0.05)$ factors for the variations in the average cluster BMI values of women. The established direct relationship supports the conclusions by Tremmel et $a l^{77}$ that increase in body size of women is triggered by advance in age and improved socioeconomic status of households. The findings also showed that, irrespective of the educational status, type of place of residence and marital status improvements in livelihoods of women and increase in age results in an increased likelihood of gaining more weight which subsequently results into public health burden. ${ }^{10} 48$

This study has some limitations. The lack of geographical data on individual women and their households limits the scope of the findings to the cluster level. Second, missing data on the height and weight drastically reduced the number of observations by more than half from the initial 9396 women.

\section{CONCLUSION}

This study explored and determined the spatial dimension of the overweight/obesity among reproductive women in Ghana. Results showed a $34.5 \%$ prevalence of overweight/obese among women. The study also showed that, overweight and obesity are highly prevalent among women with higher education or from wealthy households, dwell in an urban setting, and or are either married or cohabiting. Significant local clustering of overweight and or obesity were observed in the Greater Accra, Central, Western and Ashanti regions.

The estimated SLM best explained the differences in the cluster level average body weights in Ghana. The mean age of women and household wealth are significant and positive determinants of the average cluster body size (BMI). It is important to highlight that as a result of improvements in livelihoods of women, increased urbanisation coupled with the growing modernisation of diets as well the sedentary lifestyles in recent times are mostly responsible for the high rising overweight and obesity risk prevalence. The findings of the spatial modelling are limited to cluster levels due to the non-availability of georeferenced coordinates on individual women, further research with interest on the individual woman's level is therefore needed to provide further insights on the overweight and obesity burden.

Acknowledgements We are very grateful to the DHS program for providing access to the datasets for this study. Our sincere thanks to Dr Mary Antwi of the Department of Environmental Management, UENR for her assistance with GIS mappings.

Contributors KAA and AOA conceptualised the study. KAA conducted the analysis and drafted the paper being supervised by AOA. IWA helped with the statistical analysis and revised the manuscript. All authors contributed to the discussion of the manuscript, read and approved the final manuscript.

Funding The authors have not declared a specific grant for this research from any funding agency in the public, commercial or not-for-profit sectors.

Map disclaimer The depiction of boundaries on this map does not imply the expression of any opinion whatsoever on the part of BMJ (or any member of its group) concerning the legal status of any country, territory, jurisdiction or area or of its authorities. This map is provided without any warranty of any kind, either express or implied.

\section{Competing interests None declared.}

Patient and public involvement Patients and/or the public were not involved in the design, or conduct, or reporting or dissemination plans of this research.

\section{Patient consent for publication Not required.}

Ethics approval Ethical approval for the GDHS was granted by the ICF International Institutional Review Board (IRB) and Ghana Health Service Ethical Committee.

Provenance and peer review Not commissioned; externally peer reviewed.

Data availability statement Data are available in a public, open access repository. The $2014 \mathrm{GDHS}$ data for this study was obtained with approval from the DHS program. The 2014 GDHS dataset is readily available in the DHS program repository. The DHS datasets are available and accessed for free after a basic process of registration.

Open access This is an open access article distributed in accordance with the Creative Commons Attribution Non Commercial (CC BY-NC 4.0) license, which permits others to distribute, remix, adapt, build upon this work non-commercially, and license their derivative works on different terms, provided the original work is properly cited, appropriate credit is given, any changes made indicated, and the use is non-commercial. See: http://creativecommons.org/licenses/by-nc/4.0/.

ORCID iD

Killian Asampana Asosega http://orcid.org/0000-0002-3140-2649

\section{REFERENCES}

1 Lavie CJ, McAuley PA, Church TS, et al. Obesity and cardiovascular diseases: implications regarding fitness, fatness, and severity in the obesity paradox. J Am Coll Cardiol 2014;63:1345-54. 
$2 \mathrm{Jnr} \mathrm{H}$, Elvis J, Asamoah N. Journal of Preventive Medicine and Care Issn No: 2474 - 3585. J Agron Res 2018;2:43-54.

3 Agofure O. Prevalence of obesity among adults in Issele-Uku, delta state Nigeria, Alexandria. J Med 2018:54:463-8.

4 Akarolo-Anthony SN, Willett WC, Spiegelman D, et al. Obesity epidemic has emerged among Nigerians. BMC Public Health 2014;14:1-9.

5 Mohamed SF, Haregu TN, Khayeka-Wandabwa C, et al. Magnitude and predictors of normal-weight central obesity- the AWI-Gen study findings. Glob Health Action 2019;12:1685809.

6 Chukwuonye II, Chuku A, John C, et al. Prevalence of overweight and obesity in adult Nigerians - a systematic review. Diabetes Metab Syndr Obes 2013;6:43-7.

7 Biadgilign S, Mgutshini T, Haile D, et al. Epidemiology of obesity and overweight in sub-Saharan Africa: a protocol for a systematic review and meta-analysis. BMJ Open 2017;7:e017666-10.

8 Price AJ, Crampin AC, Amberbir A, et al. Prevalence of obesity, hypertension, and diabetes, and cascade of care in sub-Saharan Africa: a cross-sectional, population-based study in rural and urban Malawi. Lancet Diabetes Endocrinol 2018;6:208-22.

9 Diendéré J, Kaboré J, Somé JW, et al. Prevalence and factors associated with overweight and obesity among rural and urban women in Burkina Faso. Pan Afr Med J 2019;34:1-12.

10 Ofori-Asenso R, Agyeman AA, Laar A, et al. Overweight and obesity epidemic in Ghana-a systematic review and meta-analysis. BMC Public Health 2016;16.

11 Toselli S, Gualdi-Russo E, Boulos DNK, et al. Prevalence of overweight and obesity in adults from North Africa. Eur J Public Health 2014;24 Suppl 1:31-9.

12 Popkin BM, Adair LS, Ng SW. Global nutrition transition and the pandemic of obesity in developing countries. Nutr Rev 2012;70:3-21.

13 Ajayi IO, Adebamowo C, Adami $\mathrm{H}-\mathrm{O}$, et al. Urban-rural and geographic differences in overweight and obesity in four subSaharan African adult populations: a multi-country cross-sectional study. BMC Public Health 2016;16:1-13.

14 WHO. Fact sheet No. 311 (may 2012). obesity and overweight, 2012.

15 Abubakari AR, Lauder W, Jones MC, et al. Prevalence and time trends in diabetes and physical inactivity among adult West African populations: the epidemic has arrived. Public Health 2009; 123:602-14.

16 Kelly T, Yang W, Chen C-S, et al. Global burden of obesity in 2005 and projections to 2030. Int J Obes 2008;32:1431-7.

17 Adom T, Puoane T, De Villiers A, et al. Prevalence of obesity and overweight in African learners: a protocol for systematic review and meta-analysis. BMJ Open 2017;7:e013538-4.

18 Adom T, Kengne AP, De Villiers A, et al. Prevalence of overweight and obesity among African primary school learners: a systematic review and meta-analysis. Obes Sci Pract 2019;5:487-502.

19 Klingberg S, Draper CE, Micklesfield LK, et al. Childhood obesity prevention in Africa: a systematic review of intervention effectiveness and implementation. Int J Environ Res Public Health 2019;16:1212.

20 Mohammed H, Vuvor F. Prevalence of childhood overweight/obesity in basic school in Accra. Ghana Med J 2012;46:124-7.

21 Arojo OO, Osungbade KO. Emerging issues in medical diagnosis and treatment trends of obesity epidemic and its Socio-cultural dimensions in Africa: implications for health systems and environmental interventions. Concept Press Ltd, 2013: 1-9.

22 Kim SA, Yount KM, Ramakrishnan U, et al. The relationship between parity and overweight varies with household wealth and national development. Int J Epidemiol 2007;36:93-101.
23 Benkeser RM, Biritwum R, Hill AG. Prevalence of overweight and obesity and perception of healthy and desirable body size in urban, Ghanaian women. Ghana Med J 2012;46:66-75.

24 GSS, GHS, and ICF International. Demographic and health survey, 2015. https://dhsprogram.com/pubs/pdf/FR307/FR307.pdf

25 Desa and U.N. World population prospects 2019: highlights. New York (US), 2019.

26 Selase AE, Lu X. The impact of Ghana government poverty alleviation actions in the National poverty eradication programme. SRN Electronic Journal 2018:1-25.

27 Cressie NAC. Statistics for spatial data, revised edition. Biometrics 1994;50:319.

28 Getis A, Ord JK. The analysis of spatial association by use of distance statistics. Geogr Anal 1992;24:189-206.

29 Anselin L. Local indicators of spatial Association-LISA. Geogr Anal 1995;27:93-115.

30 Cliff JK. Spatial processes: models \& applications. Taylor Fr, 1981.

31 Anselin L. Lagrange multiplier test diagnostics for spatial dependence and spatial heterogeneity. Geogr Anal 1988;20:1-17.

32 Moran PA. Biometrika trust a test for the serial independence of residuals. Oxford University Press on behalf of Biometrika Trust Stable, 2016: 178-81. http://www.jstor.org/stable/2332162

33 Moran PAP. A test for the serial independence of residuals. Biometrika 1950;37:178-81.

34 Ord K. Estimation methods for models of spatial interaction. J Am Stat Assoc 1975;70:120-6.

$35 \mathrm{Lu} \mathrm{J}$, Zhang L. Evaluation of parameter estimation methods for fitting spatial regression models. Forest Science 2010;56:505-14.

36 Akaike $\mathrm{H}$. A new look at the statistical model identification. IEEE Trans Automat Contr 1974;19:716-23.

37 Schwarz G. Estimating the dimension of a model. Ann. Statist. 1978;6:461-4.

38 Stone M. Comments on Model Selection Criteria of Akaike and Schwarz Author (s): M. Stone Source : Journal of the Royal Statistical Society. Series B (Methodological), Vol. 41, No. 2. Blackwell Publishing for the Royal Statistical Society Sta, R. Stat. Soc, 2009: 276-8

39 Musaiger AO. Overweight and obesity in eastern Mediterranean region: prevalence and possible causes. J Obes 2011;2011:1-17.

40 Ziraba AK, Fotso JC, Ochako R. Overweight and obesity in urban Africa: a problem of the rich or the poor? BMC Public Health 2009;9:1-9.

41 Seidell JC, Halberstadt J. The global burden of obesity and the challenges of prevention. Ann Nutr Metab 2015;66 Suppl 2:7-12.

42 Averett SL, Sikora A, Argys LM. For better or worse: relationship status and body mass index. Hum Biol 2008;6:330-49.

43 Fitzgibbons Shafer E, Shafer EF. The effect of marriage on weight gain and propensity to become obese in the African American community. J Fam Issues 2010;31:1166-82.

44 Wilson SE. Marriage, gender and obesity in later life. Econ Hum Biol 2012;10:431-53

45 Teachman J, Weight B. Body weight, marital status, and changes in marital status. J Fam Issues 2016;37:74-96.

46 yemane Nguse T. Childhood Obesity \& Child Development. Atlanta, USA: Child Obes Child Dev, 2016: 7904.

47 Tremmel M, Gerdtham U-G, Nilsson PM, et al. Economic burden of obesity: a systematic literature review. Int $J$ Environ Res Public Health 2017;14:435-18.

48 Taylor VH, Forhan M, Vigod SN, et al. The impact of obesity on quality of life. Best Pract Res Clin Endocrinol Metab 2013;27:139-46. 